\title{
Mediational paths from supervisor support to turnover intention and actual turnover among community mental health providers
}

\author{
Sadaaki Fukui, Ph.D \\ Associate Professor, Indiana University School of Social Work, 902 West New York Street, \\ Indianapolis, IN 46202-5156 USA
}

Wei Wu, Ph.D

Associate Professor, Indiana University-Purdue University Indianapolis, Department of Psychology, 402 N. Blackford St., LD120c Indianapolis, IN 46202-3217 USA

Michelle P. Salyers, Ph.D

Professor, Indiana University-Purdue University Indianapolis, Department of Psychology, 402 N. Blackford St., LD124 Indianapolis, IN 46202-3217 USA

Address correspondence to:

Sadaaki Fukui, Ph.D.

Associate Professor, Indiana University School of Social Work 902 West New York Street, Indianapolis, IN 46202-5156 USA

TEL: 317-278-1767; Email: sadafuku@iu.edu

Acknowledgements and Disclosures: The study was supported by Patient-Centered Outcomes Research Institute (IH-1304-6597). The content is solely the responsibility of the authors and does not represent the official views of PCORI

This is the author's manuscript of the article published in final edited form as:

Fukui, S., Wu, W., \& Salyers, M. P. (2019). Mediational paths from supervisor support to turnover intention and actual turnover among community mental health providers. Psychiatric Rehabilitation Journal, 42(4), 350-357. https://doi.org/10.1037/prj0000362 


\begin{abstract}
Objective: Turnover is a critical problem for community mental health providers, and supervisors may play an important role in mitigating turnover. The current study examined the potential impact of supervisory support on turnover intention and actual turnover among community mental health providers. Methods: We conducted path analyses with data collected longitudinally from 186 direct clinical care providers at two community mental health centers. Results: Increased supervisory support was associated with lower turnover intention 6 months later, as well as reduced actual turnover 12 months later. Type of supervisory support mattered: supervisors' emotional support was most strongly associated with reduced turnover intention and turnover. However, client goal alignment support (supporting providers to help consumers achieve their goals) was directly associated with increased turnover. Conclusions and Implications for Practice: The current study suggests an important role for direct supervisors to attend to care providers' emotional support needs, which may reduce turnover intention and actual turnover. Differential supervisory support functions might impact turnover in unique ways; thus, examining more detailed change mechanisms would facilitate our understanding of factors that may prevent future turnover.

Keywords: Supervision; Turnover Intention; Turnover; Mediation Analysis; Longitudinal Study
\end{abstract}

\title{
Impact and Implications
}

The current study suggests an important role for direct supervisors to attend to mental health care providers' emotional support needs, which may potentially reduce turnover intention and actual 
turnover. Given the high rates of turnover and associated costs to mental health organizations, this study provides important information for organizational leaders.

\section{Introduction}

Mental health care systems in the United States have faced significant workforce challenges. In particular, provider turnover is a critical problem for many community mental health organizations, with rates of turnover ranging from $25 \%$ to $60 \%$ annually, depending on the organization and type of position (Aarons \& Sawitzky, 2006; Beidas et al., 2016; Bukach, Ejaz, Dawson, \& Gitter, 2017). Although turnover is not always detrimental (e.g., Holtom, Mitchell, Lee, \& Eberly, 2008), high rates can be costly both for organizations (e.g., extra cost for new hires and training, reduced productivity) and individual providers (e.g., diminished well-being, reduced financial stability) (Aarons \& Sawitzky, 2006; Bukach et al., 2017; Eby, Burk, \& Maher, 2010; Hoge et al., 2007; Knudsen, Ducharme, \& Roman, 2008), and turnover can ultimately impact quality of care for consumers (e.g., Brandt, Bielitz, \& Georgi, 2016; Rollins, Salyers, Tsai, \& Lydick, 2010; Woltmann et al., 2008). Organizations need ways to mitigate turnover.

Turnover research frequently distinguishes two main constructs -- intention and actual turnover. In empirical research, turnover intention (i.e., thoughts and sometimes behaviors associated with the intention to leave a job) has been examined more frequently than actual turnover (Cohen, Blake, \& Goodman, 2016), and actual turnover data are not always available for researchers, for example, because of the need for longitudinal data collection or access to administrative records. Accordingly, turnover intention often serves as a proxy outcome for turnover and is considered a reliable predictor for actual turnover (Hom, Lee, Shaw, \& Hausknecht, 2017). Further, turnover intention is also an important outcome in itself. For example, it is more feasible for organizations to intervene when employees are considering 
leaving, rather than after they have already left. However, research also indicates the distinct nature of the two constructs. For example, Cohen et al. (2016) found that turnover intentions explained less than $5 \%$ of variance in actual turnover among public employees. This may be due to the differences in measurement (i.e., subjective vs. objective indicators) as well as external factors that may not linearly translate the intended action (e.g., health status, family issues, job opportunities) (Cohen et al., 2016). Understanding factors and mechanisms that might predict both reduced intention as well as actual turnover is important.

A variety of models have been put forth to understand turnover and the factors that lead to it (e.g., Holtom et al., 2008; Lee \& Mitchell, 1994; Mitchell, Holtom, Lee, Sablynski, \& Erez, 2001). However, most view turnover as a process that develops over time. For example, Mobley's model (Mobley, 1977) identifies processes that lead to people to consider leaving (turnover intentions) which lead to actually leaving. While turnover can occur outside of intentions, for example, with jarring events such as unsolicited job offers (Holtom, Mitchell, Lee, \& Inderrieden, 2005; Lee \& Mitchell, 1994), turnover reasearch has suggested that intentions are often a proximinate precursor to consequent turnover action (Hom et al., 2017; Steel \& Ovalle, 1984).

Research has also identified preventive factors for turnover, and supervisors could play a critical role in mitigating turnover intentions and consequent turnover, which may be particularly important for mental health settings. Mental health providers often work more than their scheduled work hours to manage work demands (Luther et al., 2017). Direct service providers also tend to have little professional training, which makes their work more challenging (e.g., Eack, Greeno, Christian-Michaels, Dennis, \& Anderson, 2009; Hoge et al., 2007). Because of high job demands in helping consumers with complex needs, provider burnout is common in 
mental health (Morse, Salyers, Rollins, Monroe-DeVita, \& Pfahler, 2012). All these factors suggest the importance of providing support on the job. Indeed, several studies indicate the importance of increasing organizational support, especially from supervisors, when addressing turnover (Coomber \& Barriball, 2007; Knudsen, Ducharme, \& Roman, 2008; Yanchus, Periard, \& Osatuke, 2017). For example, Smith (2005) found that child welfare providers who reported having more supportive and competent supervisors, were more likely to stay 15-17 months later. However, we are not aware of studies examining differential aspects of supervisory support to reduce turnover intentions, and potentially prevent actual turnover, among mental health providers using longitudinal data.

Supervisors may serve a number of different functions that could lead to reduced turnover within an organization. Kadushin \& Harkness (2014) describe three primary functions of supervision, including administrative (organizational management), educational (professional development), and supportive (expressive, emotionally supportive leadership). Among these functions, the administrative function is rarely perceived as helping providers work with consumers (Fukui, Rapp, Goscha, Marty, \& Ezell, 2014). On the other hand, supportive and educational functions have received increased attention in recent years (O'Donoghue \& Tsui, 2013). In particular, having a supportive supervisor is important in mitigating turnover risk factors such as work stress (Hyrkäs, Appelqvist-Schmidlechner, \& Haataja, 2006; Kim \& Lee, 2009; Martin \& Schinke, 1998; O'Donoghue \& Tsui, 2013). In addition, given the current emphasis on providing high quality services, educational support for professional development is critical and may help retain quality workers (e.g., Price \& Reichert, 2017). Further, with the increased attention to consumer-centered practices in mental health, a fourth function has been advocated (e.g., Fukui et al., 2014; Rapp, Goscha, \& Fukui, 2015) -- supporting providers to help 
consumers achieve their goals (i.e., client goal alignment support function). Supervisory support to help providers to better engage with consumers is critical in mental health (e.g., Eack et al., 2009; Fukui et al., 2014; Rapp et al., 2015). Such support may help retain quality workers. For example, greater use of consumer-centered practices was related to reduced employee turnover intention in hospital settings (Avgar, Givan, \& Liu, 2011). Similarly, consumer-centered attitudes may serve as internal resources (e.g., increased motivation, increased focus/prioritization on job roles helping consumers) for providers to cope with job related stressors, which could increase job retention (e.g., Babakus, Yavas, \& Karatepe, 2017).

The purpose of this study is to empirically test the impact of supervisory support on intended and actual turnover among community mental health providers. Using prospective, longitudinal data, we examine the impact of three differential supervisory support functions (i.e., emotional support, client goal alignment support, professional development support) on turnover intention and actual turnover. We hypothesize that providers who perceive more support from their direct supervisors in each of these domains will be less likely to think about leaving their jobs and ultimately will be less likely to actually leave. The current study fills a gap in turnover research by empirically testing the relationship among differential supervisory support, turnover intention, and actual turnover using longitudinal data. Given the high rates of turnover and associated costs to mental health organizations, this study provides important information for organizational leaders for ways to potentially intervene.

\section{Methods}

Participants and Setting 
We conducted secondary analyses using data from a randomized, controlled trial (Author, in press) comparing BREATHE, a burnout-reduction focused intervention (Rollins et al., 2016; Salyers et al., 2011) to Motivational Interviewing training (Miller \& Rollnick, 2012). The data were collected from 195 direct clinical care providers at two Midwestern community mental health centers (rural and urban locations) over a 12-month period. The rural location was a public, non-profit organization that employed approximately 230 staff at the time of the study, providing community-based substance abuse and mental health services to nearly 6000 consumers annually. The urban location was also a public, non-profit organization that employed approximately 260 staff serving nearly 4000 consumers annually. Both organizations were providing case management, home-based and school-based services, supported employment, medication management, and outpatient individual and group services.

Participants answered online surveys, and received a \$10 gift card for the completion of each survey. In addition, we obtained actual turnover data (i.e., whether they left the organizations) from their organizations at 12 months after the baseline survey. The majority of participants were white (85\%) and female (80\%), and the average age was $40( \pm 12)$ years old. The average length in the current position was $3.3( \pm 4.7)$ years. By 12 months, $29 \%(n=56)$ left the organizations (actual turnover). Among those who left the organizations, $86 \%(\mathrm{n}=48)$ left voluntarily (including one person who retired) and $14 \%(n=8)$ were terminated. Further, turnover data were not available for one case. Because voluntary turnover is often an interest in turnover research (e.g., Cho \& Song, 2017; Holtom et al., 2008; Hom et al., 2017) and the associated factors may be different (Bukach et al., 2017), we excluded terminations $(\mathrm{n}=8)$ along with missing $(n=1)$ cases for the analyses in this study. Thus, the total sample size for this study was 186 cases. The original study (Authors, in press) was approved by [the university's] Institutional 
Review Board. The original study did not find any significant intervention effects on measures used in this study.

Measures

Our independent variable, supervisory support, was measured by the Perception of Supervisory Support (PSS) Scale (Fukui et al., 2014). The PSS Scale measures perceived supervisory support from the perspective of direct mental health service providers in three domains (each a subscale): emotional support (e.g., how often the provider leaves supervision feeling energized), support for client goal alignment (e.g., how often the provider achieves better alignment between a consumer's goal and their goal for the consumer), and support for professional development (e.g., how often the provider gets feedback on performance). The scale consists of 19 items, with a 6-point Likert scale ranging from 1 (never) to 6 (always), such that higher numbers indicate more support. The scale has good content validity and reliability (Fukui et al., 2014). The internal consistency for the current sample was good (emotional support, 10 items, Cronbach's alpha $=0.96$; client goal alignment support, 5 items, alpha $=0.96$; professional development support, 4 items, alpha $=0.83$ at baseline). We used the baseline PSS subscale scores to predict the mediating and dependent outcomes (turnover intention at 6 months and actual turnover at 12 months, respectively).

Turnover intentions were assessed by two self-report items at 6 months. The first item, "How often have you seriously considered leaving your job in the past six months?" was rated on a 6-point scale from 1 (Never) to 6 (Several times a week). The second item asked "How likely are you to leave your job in the next six months?" on a 4-point scale ranging from 1 (Not likely at all) to 4 (Very likely). These items have been used in several studies with community mental health clinicians and have been found to correlate with burnout and job satisfaction (e.g., Salyers 
et al., 2015). The correlation between the two items was high $(r=.70)$, so we computed one turnover intention score, by rescaling the second item to a 6-point scale and taking the mean of the two items.

Actual turnover, the dependent variable, was obtained from each organization for each participant at 12 months following the initial baseline survey. Those who remained at the organization at 12 months were coded as 0 while those who left were coded as 1 (= voluntary turnover, including retirement).

\section{Analyses}

We used path analyses in structural equation modeling to examine the direct and indirect effects of differential supervisory support domains (i.e., emotional support, client goal alignment support, professional development support) on actual turnover through turnover intention. Namely, we examined whether the baseline supervisory support predicts turnover intentions at 6 months, which in turn predicts actual turnover at 12 months.

Our primary interest was to examine the impact of the differential aspects of supervisory support on turnover; and whether there are unique patterns between the differential supervisory support functions in the path that turnover intentions to lead actual turnover. In addition, because the supervisory support functions are correlated to one another (ranging from $r=0.61$ to 0.78 ), our secondary interest was to examine the unique effect of the differential supervisory support functions in predicting outcomes by controlling for other supervisory support functions. Thus, we first tested the mediation effects for each of the three supervisory support domains independently (i.e., emotional support [model 1, Figure 1], client goal alignment support [model 2, Figure 1], professional development support [model 3, Figure 1]). We then tested the combined model (model 4, Figure 2), which allows us to evaluate the effect of a supervisory 
support domain controlling for the other two. In the path analyses, the continuous mediator (i.e., turnover intention) was predicted using a linear regression. The binary outcome (i.e., turnover) was predicted using probit regression, assuming that there was a normal latent variable underlying the binary outcome. Thus, any path pointing to the binary outcome will capture an effect on the underlying latent variable.

Traditionally, an indirect effect is quantified by the product of two coefficients (the coefficient of a dependent variable $[\mathrm{Y}]$ on a mediator variable $[\mathrm{M}]$ controlling for an independent variable $[\mathrm{X}]$, and the coefficient of $\mathrm{M}$ on $\mathrm{X})$. However, this approach is not appropriate when either Y, M or both are categorical (Muthén, Muthén, \& Asparouhov, 2017). In our study, turnover $(\mathrm{Y})$ is a binary variable. We thus tested direct and indirect effects using a counterfactual approach described in Robins and Greenland (1992), which has been implemented in Mplus (Muthén \& Muthén, 1998-2017). Comparing to the traditional approach, counterfactually defined indirect and direct effects are generalizable to categorical mediators and outcomes. The indirect and direct effects defined by this approach may be also expressed in odds ratios (see VanderWeele \& Vansteelandt, 2010). Given that odds ratios are commonly reported in data analyses for binary outcomes, we presented the direct and indirect effects in odds ratios and tested their significance using bootstrap confidence intervals (CIs) obtained from 5000 bootstrap samples. Note that the CI for an odds ratio indicates a significant effect if it does not cover 1 . Testing a mediation effect typically requires larger samples than we had access to, especially given that we have a categorical outcome. Accordingly, we accepted significance at $p<0.10$ $(90 \% \mathrm{CI})$ to avoid potential type II error.

Robust full information maximum likelihood method was used to estimate the model, which is an appropriate method to handle incomplete data as well as nonnormality of the 
categorical outcome. We had about $26 \%$ incomplete cases overall mostly due to turnover. In all of the models, age (years), site (organizations), intervention (BREATHE vs. MI), gender (Male vs. Female), race (White vs. non-White), and years in the current position were included as covariates. All of the analyses were conducted using Mplus 8 (Muthén \& Muthén, 1998-2017).

\section{Results}

In our data, $26 \%$ of participants voluntarily left their organizations by 12 months (48 out of 186). Turnover intentions at 6 months explained $12 \%$ of the variance of actual turnover at 12 months.

Our individual predictor models are shown in Figure 1. The result for model 1 (see figure 1) suggests that increased emotional support was associated with decreased turnover intention at six months $\left(B^{I}=-0.48, \beta=-0.35, p<0.01\right)$, which was associated with decreased actual turnover at 12 months $(B=0.25, \beta=0.36, p<0.01)$, holding the covariates constant. The indirect effect (emotional support $\rightarrow$ turnover intention $\rightarrow$ turnover) was significant (odds ratio $=0.80,95 \%$ $[0.63,0.94])$, indicating that for one SD increase in emotional support, the odds of turnover decreased by $20 \%$ via its influence on turnover intention, controlling for the covariates. The direct effect of emotional support was not significant.

The result for model 2 (see Figure 1) suggests that increased client goal alignment support was associated with decreased turnover intention at six months $(B=-0.43, \beta=-0.31, p<$ $0.01)$, which was associated with decreased turnover at 12 months $(B=0.28, \beta=0.39, p<0.01)$. The indirect effect (client goal alignment support $\rightarrow$ turnover intention $\rightarrow$ turnover) was significant (odds ratio $=0.80,95 \% \mathrm{CI}[0.63,0.94]$ ), indicating that for one SD increase in client goal alignment support, the odds of turnover decreased by $20 \%$ via its influence on turnover

\footnotetext{
${ }^{1} \mathrm{~B}$ represents an unstandardized coefficient, and $\beta$ represents a standardized coefficient.
} 
intention, controlling for the covariates. In addition, we found a significant direct effect, but in the opposite direction. The odds ratio was 1.52 for the direct effect with $95 \%$ CI [1.06, 2.65], indicating that one SD increase in client goal alignment support increased the odds of turnover by $52 \%$, controlling for turnover intention and the covariates.

The result for model 3 (see Figure 1) suggests that increased professional development support was associated with decreased turnover intention at six months $(B=-0.25, \beta=-0.18, p=$ 0.04), which was associated with decreased turnover at 12 months $(B=0.24, \beta=0.35, p=0.02)$. The indirect effect (professional development support $\rightarrow$ turnover intention $\rightarrow$ turnover) was significant (odds ratio $=0.89,95 \% \mathrm{CI}[0.74,1.00]$ ), indicating that for one SD increase in professional development support, the odds of turnover decreased by $11 \%$ via its influence on turnover intention, controlling for the covariates. The direct effect of professional development support was not significant.

Finally, the result for model 4 (see Figure 2) suggests that although all three supervisory support domains showed significant indirect effects when considered individually, only the indirect effect for emotional support was significant at $p<0.10$ (odds ratio $=0.81,90 \%$ CI $[0.58$, 0.98]), after controlling for the others. Further, client goal alignment support had a stronger positive direct effect on turnover $(B=0.42, \beta=0.42, p=0.04)$ after controlling for the other two supervisory support domains. The odds ratio for the direct effect was 2.15 (95\% CI [1.17, 5.50]), suggesting that one SD increase in client goal alignment support resulted in $115 \%$ increase of the odds of turnover, if any portion of client goal alignment support that is redundant with the other two domains was removed.

\section{Please insert Figures $1 \& 2$ around here}

\section{Discussion}


The current study examined the impact of supervisory support (i.e., emotional, client goal alignment, and professional development support) on turnover intention and actual turnover among community mental health providers. This is the first study we are aware of that tested these relationships using longitudinal data. This is important as longitudinal models reduce potentially biased estimates that are problematic in cross-sectional mediation analyses (Maxwell \& Cole, 2007) and help clarify potential directionality in relationships. We found that increased supervisory support was associated with reduced turnover intention 6 months later, and decreased turnover at the end of a 12-month period. The indirect effect was present across each of the differential supervisory support domains. However, after controlling for each domain together, only emotional support continued to have a significant indirect effect. Further, contrary to expectations, client goal alignment support was directly associated with increased turnover 12 months later alone and after controlling for the other supervisory support impacts. Finally, turnover intention explained $12 \%$ of variance in actual turnover among community mental health providers.

Although we cannot make causal claims in our study, our findings are consistent with an explanatory model in which increased supervisory support could reduce future turnover by reducing turnover intention among mental health providers. These findings are further strengthened in our ability to examine mediational tests longitudinally, where the mediator is measured at a later time from the predictor variable of interest. Supervisory support, in particular emotional support, may be critical in reducing excessive turnover. As previous research suggests, increased supervisory support may help mitigate negative factors (e.g., job stressors), leading to reduced turnover intention (e.g., Morazes, Benton, Clark, \& Jacquet, 2010; O'Donoghue \& Tsui, 2013). By providing emotional support and reducing intention, we may then prevent future 
actual turnover. This finding has important implications in practice as increased supervisory support may be more attainable (e.g., training supervisors, encouraging more time for supervision) than other structural/organizational level changes (e.g., increasing pay, creating promotion opportunities). This implication may be particularly important given significant financial constraints among mental health organizations (e.g., Bond \& Drake, 2017).

On the other hand, we unexpectedly found that increased client goal alignment support adversely increased actual turnover after controlling for turnover intention. We had expected client goal alignment would be associated with lower turnover. For example, consumer-centered approaches, that are consistent with supporting consumer goals, have been positively correlated with improved job attitudes among providers (e.g., satisfaction, loyalty, commitment; TellisNayak, 2007). In addition, consumer-centered practices could increase providers' work engagement, and serve as internal resources to handling challenging situations and reducing turnover intention (e.g., Babakus et al., 2017).

There are several possibilities to consider for our contradictory findings. One possibility is that increased encouragement by direct supervisors for achieving consumer goals could be perceived as increased work demand for providers. The consumer-centered practice philosophy has become the central tenet of mental health care systems. However, translating the principal to routine practice can be challenging in daily practice (Tondora, Miller, \& Davidson, 2012). Indeed, consumer-centered practice requires the integration of a philosophy and practice tools that may not be consistent with direct providers' experiences or attitudes (Rapp \& Goscha, 2006). For example, Tondora et al. (2012) discuss frequent concerns among mental health providers for implementing consumer-centered practices, and some of which may be due to incongruence between providers' expectations and consumer-centered practice models. 
Increased demand to attend to diverse consumers' needs and goals could be challenging for providers, while simultaneously meeting other demands, such as productivity requirements. Another possibility is that client goal alignment support could increase turnover especially when it is provided in a way that is antithetical to beliefs and values of providers. For example, Bland \& Rossen (2005) discuss providers' potential moral distress that needs careful attention by supervisors who may fail to recognize the providers' experiences. Similarly, client goal alignment support could increase turnover if it compromises job autonomy for making decisions about job performance given that reduced job autonomy has been associated with increased turnover (e.g., Knudsen et al., 2008).

Finally, providers who receive more client goal alignment support could have increased job opportunities outside their organizations. For example, higher performing providers tend to leave more than lower performing providers to voluntarily seek job opportunities (e.g., Beidas et al., 2016; Eby et al., 2010). It may be that providers who received this support were doing particularly well and therefore had more opportunities outside their organization. Conversely, it may be that these providers were not performing well to begin with. They may have been receiving supervision more focused on meeting consumer goals in order to remedy a problem in their work. Although all turnover was considered "voluntary," the association with increased turnover might reflect a recognition of not performing well or not fitting with the organizational philosophy regarding consumer goals. Further research is clearly needed to understand how supervisors' attention in consumer goal alignment might lead to turnover.

Our study has several limitations. First, the study has limited generalizability due to the nature of the sample. Although the study samples reflected both urban and rural locations in Midwest who provided service typical of community mental health centers, most participants 
were white females. In addition, the data were collected within the context of an intervention study to reduce burnout. Although the original study did not find significant intervention effects on the measures in our study (Authors, in press), and the intervention conditions were controlled in our analysis, participants may be different from those in other settings. For example, it is possible that turnover rates may be different than would be expected in general community mental health settings where such intervention research is not being conducted. Second, our sample size was relatively small for testing mediation, especially for the binary turnover outcome. For example, our combined model, with all forms of supervisory support together, showed the mediation effect at the $90 \%$ CI $(p<0.10)$. Third, we were not able to account for the specific time points of turnover in the mediation models. While the turnover intention variable was measured 6 months after the supervisory support, actual turnover could have happened at any time in the 12-month follow-up period. Altogether, more detailed change mechanisms to prevent turnover are needed in order to reach a more nuanced understanding of the relationship between supervision and turnover within community mental health settings.

Despite these limitations, our study has several important implications for mental health providers and future research. With busy schedules and competing demands for time, supervision practice tends to be infrequent, and could be the first practice that may be compromised in routine practice. Our study highlights the critical roles of direct supervisors in retaining providers, particularly in providing emotional support. For example, turnover decisions can be influenced by a variety of factors (e.g., civil workplace climates, fair performance appraisal, job autonomy; Yanchus, Periard, Moore, Carle, \& Osatuke, 2015), which could be directly or indirectly related to supervisor relationships. Also, having a supportive supervisor is important in reducing work stress and increasing job commitment (e.g., O'Donoghue \& Tsui, 2013). Given 
the role of supervisors, one potential avenue of research is to find better ways to help supervisors be more effective, for example, improving interpersonal skills like empathy (e.g., Hoge, Migdole, Cannata, \& Powell, 2014).

Further, although we need to examine more nuanced mechanisms for the negative effects of client goal alignment support on actual turnover, we may infer that functions of supervision can have different effects on outcomes. Client goal alignment support is important given the primacy of consumer-centered practices (Goscha \& Rapp, 2003), and supervisors could play an important role in helping providers balance between demands for good practices and accessing

resources to reduce burden. We need to identify ways supervisors can help providers with client goal alignment without directly contributing to turnover.

Finally, our study found that turnover intention explained $12 \%$ of variance in actual turnover among mental health providers, which falls within the range of variance reported in the general literature on turnover (e.g., from 5\% to 15\% across studies; Cohen et al., 2016; Tett \& Meyer, 1993). Although we are not aware of comparable data to interpret our finding among community mental health providers, it seems clear that intention to turnover is not the primary factor in voluntarily leaving the job, at least how or when we measured intention in this study. Therefore, both intention and actual turnover may be important to study and reduce. We need more data to evaluate the predictability of turnover intention for actual turnover and the mediation mechanisms among mental health providers in different organizational settings.

\section{Conclusions}

Our study found support for a model that is consistent with paths leading from increased supervisory support to reduced turnover intention and actual turnover. Thus, increasing 
supervisory support may be helpful in reducing turnover intention and turnover. However, given that differential supervisory support functions may impact turnover differently (e.g., emotional support reduced turnover while client goal alignment support increased turnover in our study), examining more detailed change mechanisms to prevent turnover is needed in future studies. 


\section{References}

Aarons, G. A., \& Sawitzky, A. C. (2006). Organizational climate partially mediates the effect of culture on work attitudes and staff turnover in mental health services. Administration and Policy in Mental Health and Mental Health Services Research, 33(3), 289-301.

Avgar, A. C., Givan, R. K., \& Liu, M. (2011). Patient-centered but employee delivered: Patient care innovation, turnover intentions, and organizational outcomes in hospitals. ILR Review, 64(3), 423-440.

Babakus, E., Yavas, U., \& Karatepe, O. M. (2017). Work engagement and turnover intentions: Correlates and customer orientation as a moderator. International Journal of Contemporary Hospitality Management, 29(6), 1580-1598.

Beidas, R. S., Marcus, S., Wolk, C. B., Powell, B., Aarons, G. A., Evans, A. C., . . Walsh, L. M. (2016). A prospective examination of clinician and supervisor turnover within the context of implementation of evidence-based practices in a publicly-funded mental health system. Administration and Policy in Mental Health and Mental Health Services Research, 43(5), 640-649.

Bland, A. R., \& Rossen, E. K. (2005). Clinical supervision of nurses working with patients with borderline personality disorder. Issues in Mental Health Nursing, 26(5), 507-517.

Bond, G. R., \& Drake, R. E. (2017). New directions for psychiatric rehabilitation in the USA. Epidemiology and Psychiatric Sciences, 26(3), 223-227.

Brandt, W. A., Bielitz, C. J., \& Georgi, A. (2016). The impact of staff turnover and staff density on treatment quality in a psychiatric clinic. Frontiers in Psychology, 7, 457. 
Bukach, A. M., Ejaz, F. K., Dawson, N., \& Gitter, R. J. (2017). Turnover among community mental health workers in Ohio. Administration and Policy in Mental Health and Mental Health Services Research, 44(1), 115-122.

Cho, Y. J., \& Song, H. J. (2017). Determinants of turnover intention of social workers: Effects of emotional labor and organizational trust. Public Personnel Management, 46(1), 41-65.

Cohen, G., Blake, R. S., \& Goodman, D. (2016). Does turnover intention matter? Evaluating the usefulness of turnover intention rate as a predictor of actual turnover rate. Review of Public Personnel Administration, 36(3), 240-263.

Coomber, B., \& Barriball, K. L. (2007). Impact of job satisfaction components on intent to leave and turnover for hospital-based nurses: A review of the research literature. International Journal of Nursing Studies, 44(2), 297-314.

Eack, S. M., Greeno, C. G., Christian-Michaels, S., Dennis, A., \& Anderson, C. M. (2009). Case managers' perspectives on what they need to do their job. Psychiatric Rehabilitation Journal, 32(4), 309-312.

Eby, L. T., Burk, H., \& Maher, C. P. (2010). How serious of a problem is staff turnover in substance abuse treatment? A longitudinal study of actual turnover. Journal of Substance Abuse Treatment, 39(3), 264-271.

Fukui, S., Rapp, C. A., Goscha, R., Marty, D., \& Ezell, M. (2014). The perceptions of supervisory support scale. Administration and Policy in Mental Health and Mental Health Services Research, 41(3), 353-359.

Goscha, R. J., \& Rapp, C. A. (2003). The Kansas excellence in client-centered supervision program: Design and initial results. Community Mental Health Journal, 39(6), 511-522. 
Hoge, M. A., Migdole, S., Cannata, E., \& Powell, D. J. (2014). Strengthening supervision in systems of care: Exemplary practices in empirically supported treatments. Clinical Social Work Journal, 42(2), 171-181.

Hoge, M., Morris, J., Daniels, A., Stuart, G., Huey, L., \& Adams, N. (2007). An action plan for behavioral health workforce development. Cincinnati, OH: Annapolis Coalition on the Behavioral Health Workforce.

Holtom, B. C., Mitchell, T. R., Lee, T. W., \& Eberly, M. B. (2008). 5 turnover and retention research: A glance at the past, a closer review of the present, and a venture into the future. Academy of Management Annals, 2(1), 231-274.

Holtom, B. C., Mitchell, T. R., Lee, T. W., \& Inderrieden, E. J. (2005). Shocks as causes of turnover: What they are and how organizations can manage them. Human Resource Management, 44(3), 337-352.

Hom, P. W., Lee, T. W., Shaw, J. D., \& Hausknecht, J. P. (2017). One hundred years of employee turnover theory and research. Journal of Applied Psychology, 102(3), 530-545.

Hyrkäs, K., Appelqvist-Schmidlechner, K., \& Haataja, R. (2006). Efficacy of clinical supervision: Influence on job satisfaction, burnout and quality of care. Journal of Advanced Nursing, 55(4), 521-535.

Kadushin, A., \& Harkness, D. (2014). Supervision in social work. Columbia University Press.

Kim, H., \& Lee, S. Y. (2009). Supervisory communication, burnout, and turnover intention among social workers in health care settings. Social Work in Health Care, 48(4), 364385 .

Knudsen, H. K., Ducharme, L. J., \& Roman, P. M. (2008). Clinical supervision, emotional exhaustion, and turnover intention: A study of substance abuse treatment counselors in 
the Clinical Trials Network of the National Institute on Drug Abuse. Journal of Substance Abuse Treatment, 35(4), 387-395.

Lee, T. W., \& Mitchell, T. R. (1994). An alternative approach: The unfolding model of voluntary employee turnover. Academy of Management Review, 19(1), 51-89.

Luther, L., Gearhart, T., Fukui, S., Morse, G., Rollins, A. L., \& Salyers, M. P. (2017). Working overtime in community mental health: Associations with clinician burnout and perceived quality of care. Psychiatric Rehabilitation Journal, 40(2), 252-259.

Martin, U., \& Schinke, S. P. (1998). Organizational and individual factors influencing job satisfaction and burnout of mental health workers. Social Work in Health Care, 28(2), 5162.

Maxwell, S. E., \& Cole, D. A. (2007). Bias in cross-sectional analyses of longitudinal mediation. Psychological Methods, 12(1), 23.

Miller, W. R., \& Rollnick, S. (2012). Motivational interviewing: Helping people change. Guilford press.

Mitchell, T. R., Holtom, B. C., Lee, T. W., Sablynski, C. J., \& Erez, M. (2001). Why people stay: Using job embeddedness to predict voluntary turnover. Academy of Management Journal, 44(6), 1102-1121.

Mobley, W. H. (1977). Intermediate linkages in the relationship between job satisfaction and employee turnover. Journal of Applied Psychology, 62(2), 237-240.

Morazes, J. L., Benton, A. D., Clark, S. J., \& Jacquet, S. E. (2010). Views of specially-trained child welfare social workers: A qualitative study of their motivations, perceptions, and retention. Qualitative Social Work, 9(2), 227-247. 
Morse, G., Salyers, M. P., Rollins, A. L., Monroe-DeVita, M., \& Pfahler, C. (2012). Burnout in mental health services: A review of the problem and its remediation. Administration and Policy in Mental Health and Mental Health Services Research, 39(5), 341-352.

Muthén, L. K., \& Muthén, B. O. (1998-2017). Mplus user's guide. Eighth Edition. Los Angeles, CA: Muthén \& Muthén

Muthén, B. O., Muthén, L. K., \& Asparouhov, T. (2017). Regression and mediation analysis using Mplus. Los Angeles, CA: Muthén \& Muthén.

O'Donoghue, K., \& Tsui, M.-s. (2013). Social work supervision research (1970-2010): The way we were and the way ahead. The British Journal of Social Work, 45(2), 616-633.

Price, S., \& Reichert, C. (2017). The importance of continuing professional development to career satisfaction and patient care: Meeting the needs of novice to mid-to late-career nurses throughout their career span. Administrative Sciences, 7(2), 17.

Rapp, C. A., \& Goscha, R. J. (2006). The strengths model: Case management with people with psychiatric disabilities. Oxford University Press, USA.

Rapp, C. A., Goscha, R. J., \& Fukui, S. (2015). Enhanced consumer goal achievement through strengths-based group supervision. Psychiatric Rehabilitation Journal, 38(3), 268-272.

Robins, J. M., \& Greenland, S. (1992). Identifiability and exchangeability for direct and indirect effects. Epidemiology, 143-155.

Rollins, A. L., Kukla, M., Morse, G., Davis, L., Leiter, M., Monroe-DeVita, M., . . Eliacin, J. (2016). Comparative effectiveness of a burnout reduction intervention for behavioral health providers. Psychiatric Services, 67(8), 920-923.

Rollins, A. L., Salyers, M. P., Tsai, J., \& Lydick, J. M. (2010). Staff turnover in statewide implementation of ACT: Relationship with ACT fidelity and other team 
characteristics. Administration and Policy in Mental Health and Mental Health Services Research, 37(5), 417-426.

Salyers, M. P., Fukui, S., Rollins, A. L., Firmin, R., Gearhart, T., Noll, J. P., . . Davis, C. (2015). Burnout and self-reported quality of care in community mental health. Administration and Policy in Mental Health and Mental Health Services Research, 42(1), 61-69.

Salyers, M. P., Hudson, C., Morse, G., Rollins, A. L., Monroe-DeVita, M., Wilson, C., \& Freeland, L. (2011). BREATHE: A pilot study of a one-day retreat to reduce burnout among mental health professionals. Psychiatric Services, 62(2), 214-217.

Smith, B. D. (2005). Job retention in child welfare: Effects of perceived organizational support, supervisor support, and intrinsic job value. Children and Youth Services Review, 27(2), 153-169.

Steel, R. P., \& Ovalle, N. K. (1984). A review and meta-analysis of research on the relationship between behavioral intentions and employee turnover. Journal of Applied Psychology, 69(4), 673-686.

Tellis-Nayak, V. (2007). A person-centered workplace: the foundation for person-centered caregiving in long-term care. Journal of the American Medical Directors Association, 8(1), 46-54.

Tett, R. P., \& Meyer, J. P. (1993). Job satisfaction, organizational commitment, turnover intention, and turnover: Path analyses based on meta-analytic findings. Personnel Psychology, 46(2), 259-293. 
Tondora, J., Miller, R., \& Davidson, L. (2012). The top ten concerns about person-centered care planning in mental health systems. International Journal of Person Centered Medicine, $2(3), 410-420$.

VanderWeele, T. J., \& Vansteelandt, S. (2010). Odds ratios for mediation analysis for a dichotomous outcome. American Journal of Epidemiology, 172(12), 1339-1348.

Woltmann, E. M., Whitley, R., McHugo, G. J., Brunette, M., Torrey, W. C., Coots, L., ... \& Drake, R. E. (2008). The role of staff turnover in the implementation of evidence-based practices in mental health care. Psychiatric Services, 59(7), 732-737.

Yanchus, N. J., Periard, D., Moore, S. C., Carle, A. C., \& Osatuke, K. (2015). Predictors of job satisfaction and turnover intention in VHA mental health employees: A comparison between psychiatrists, psychologists, social workers, and mental health nurses. Human Service Organizations: Management, Leadership \& Governance, 39(3), 219-244.

Yanchus, N., Periard, D., \& Osatuke, K. (2017). Further examination of predictors of turnover intention among mental health professionals. Journal of Psychiatric and Mental Health Nursing, 24(1), 41-56. 
Figure 1

Supervisory support predicting turnover through turnover intention (Separate models)

(model 1)

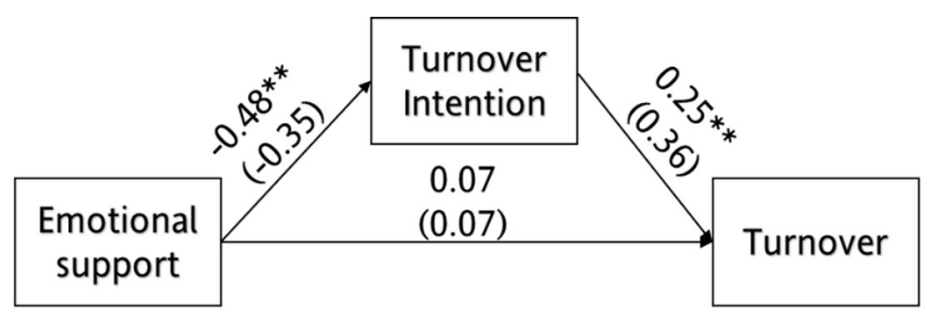

Indirect (Odds ratio $)=0.80 * *$

Direct (Odds ratio) $=1.07$

(model 2)

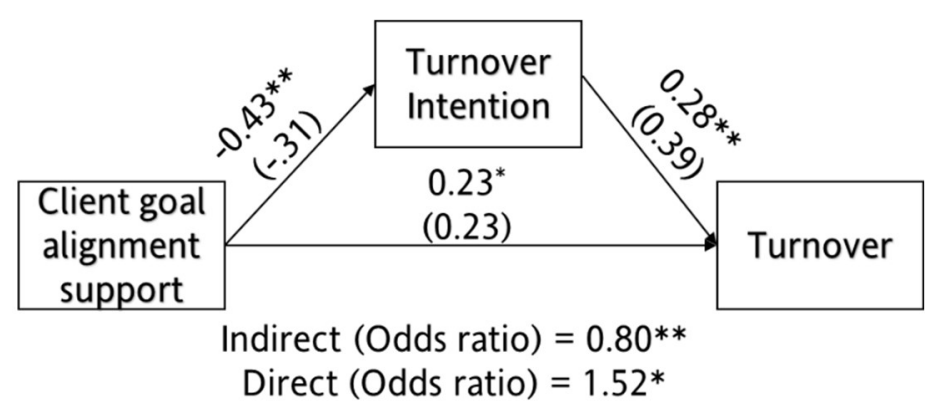

(model 3)

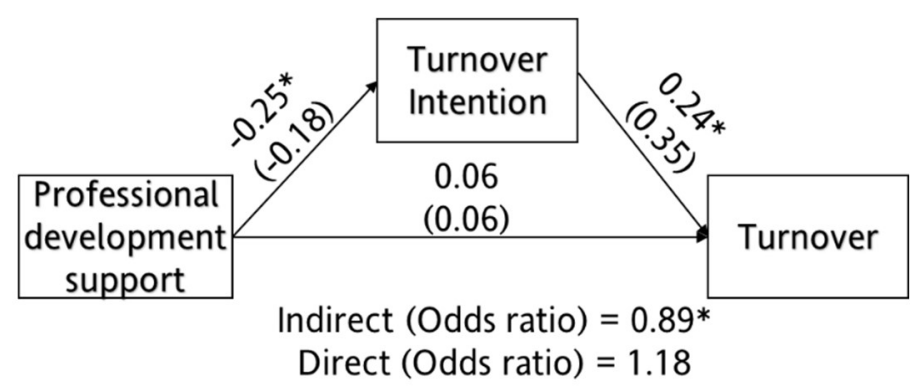

Figure 1. The mediation models for the three supervision domains separately (models 1-3). The coefficients inside and outside of the parentheses are standardized and unstandardized partial regression coefficients, respectively. The coefficients for the paths pointing to turnover intention are linear regression coefficients. The coefficients for the paths pointing to turnover are probit regression coefficients. Note that for simplicity, covariates are omitted in the diagrams. The indirect and direct effects are presented as odds ratios. ${ }^{*} p<0.05 ; * * p<0.01$. 
Figure 2

Supervisory support predicting turnover through turnover intention (Combined model: model 4)

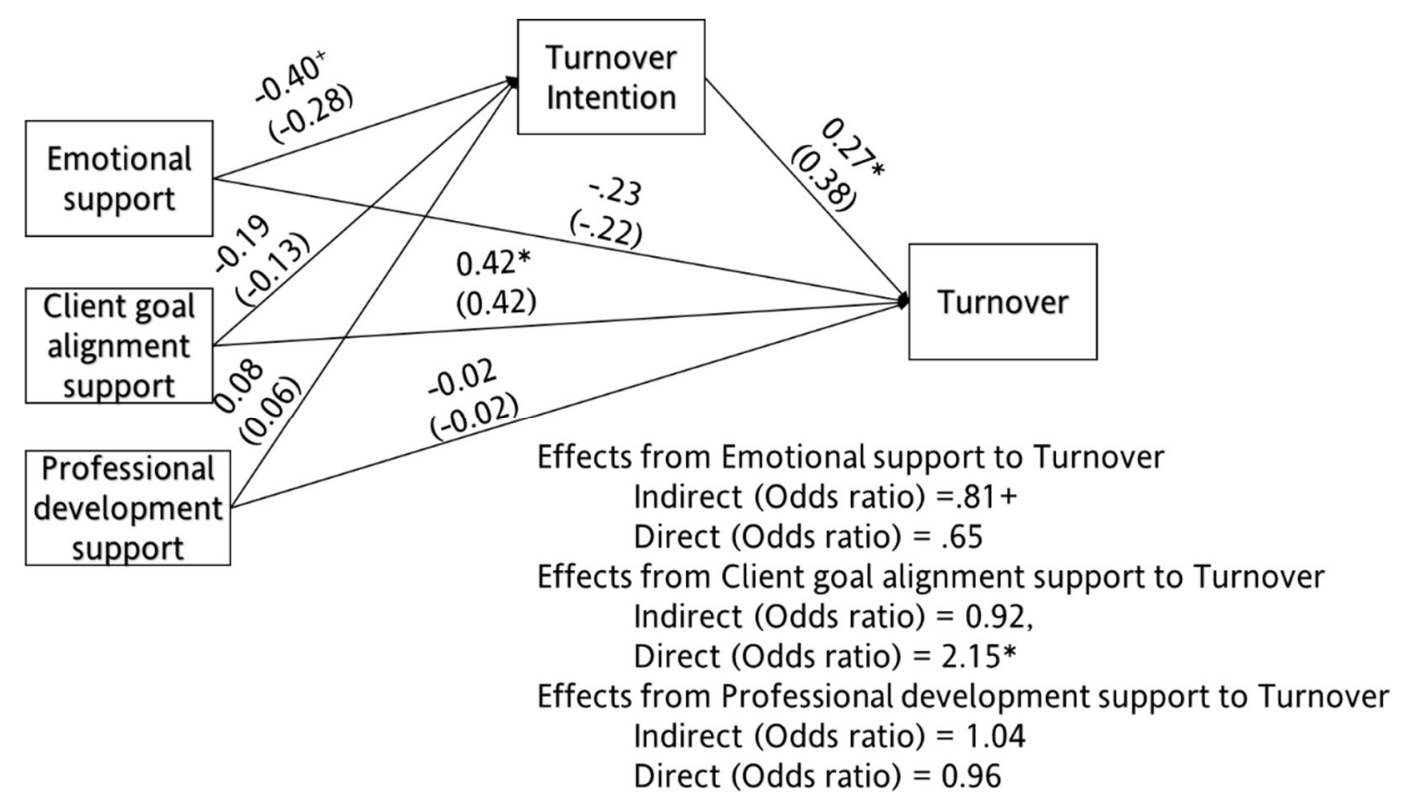

Figure 2. The mediation model with all three supervision domains (model 4). The coefficients inside and outside of the parentheses are standardized and unstandardized partial regression coefficients, respectively. The coefficients for the paths pointing to turnover intention are linear regression coefficients. The coefficients for the paths pointing to turnover are probit regression coefficients. Note that for simplicity, covariates are omitted in the diagram. The indirect and direct effects are presented as odds ratios. Both $90 \%$ and $95 \%$ CIs are reported. If a CI covers 1 , then the corresponding effect was not significant. ${ }^{+} p<0.10 ;{ }^{*} p<0.05 ; * * p<0.01$ 